\title{
An Evaluation of Agri-Environmental Indicators through a Multi-Criteria Decision-Making Tool in Germany, France, the Netherlands, and Turkey
}

\author{
Serkan Gürlük*, Gokhan Uzel \\ Uludağ University, Department of Agricultural Economics, Bursa, Turkey
}

Received: 23 November 2015

Accepted: 9 March 2016

\begin{abstract}
Our study investigates the historical achievements of agri-environmental and economic policies in order to ensure food security in the nations of Germany, France, the Netherlands, and Turkey. Various agroeconomic and environmental indicators are tested, such as per capita cereals, per capita meat production, per capita milk production, yield of cereals, gross agricultural production value, fertilizer and pesticide use efficiency, and total agricultural emissions. The study attempts to rank the countries according to sustainability criteria. In the studies of ranking, multi-criteria decision-making methods are best suited for effectively dealing with a number of multifaceted evaluation criteria. The current study employs the technique for order preference by similarity to ideal solution method to rank the countries according to the above-mentioned criteria. Results show that Turkey was the closest to an optimal solution in 1980, while the Netherlands was farthest from an optimal solution the same year. In 2013 the country closest to an optimal solution was France. We can infer that economic indicators have some effects on ideal solutions because the Netherlands has less agricultural land, but its agri-economic value is higher than in other countries.
\end{abstract}

Keywords: multi-criteria decision making, land use policy, sustainability, TOPSIS

\section{Introduction}

The effects of climate change, drought predictions, urbanization, and industrialization efforts has increased by too much the importance of agri-environmental policies in developing countries. The policies of providing food security have gained importance with the effects of the above-mentioned topics. To a certain extent countries

*e-mail: serkan@uludag.edu.tr need the use of natural resources to ensure self-sufficiency and competitiveness in foreign trade in agriculture. However, environmental issues are an inevitable phenomenon. Increasing environmental problems can be resolved with the concept of efficiency in Economics. Self-sufficiency in agriculture, inputs, and agricultural production value from unit value are also considered in the concept of efficiency. Evaluating environmental risk factors requires linguistic terms to be used rather than exact numerical assignments.

The fuzzy set theory provides a useful tool for converting linguistic terms into numerical evaluation [1-2]. 
In various countries, several studies have been performed to explain environmental issues by using the multi-criteria decision-making tool depending on fuzzy set theory. Some chemical indicators and social statistics were integrated into a study evaluating the health of a lake ecosystem [3]. Historical data recorded the years 2008 and 2013 in Poyang Lake, and some environmental management actions were suggested according to results. In a study from the energy sector, the environmental risk assessment of a gas power plant exploitation unit was evaluated depending on technique for order of preference by similarity to ideal solution (TOPSIS) methodology [4].

The most vulnerable areas in the soil erosion issue were determined by a multi-criteria decision analysis method in Serbia's Topciderska River. Parameters were land use, soil characteristics, and mean watershed slope without economic data [5]. It was proven that TOPSIS can provide a comprehensive and accurate assessment of sediment quality and efficiently discriminate risks among different sites, including environmental risk assessment [6]. If agri-environmental indicators are supported by economic indicators, they would be useful for public opinion and policy makers. The novelty of this paper is the use of economic indicators.

The current study contributes to existing literature by using economic indicators alongside agri-environmental ones. It is stressed by some authors that economics and the environment were the main criteria in the ranking [78]. In this scope, all sectors were analyzed using TOPSIS with the help of macro data, and in Iran, polluting sectors were determined with the support of input-output analysis [9]. In addition, some studies support the idea of agri-environmental parameters and the importance of multicriteria decision-making tools. A model suggested by [10] as a tool for better management of coral reef ecosystem services is driver pressure state impact response (DPSIR), which could be considered an attempt to use management systems - including the multi-objective decision modeling system.

The importance of agri-environmental and economic parameters was stressed by a study carried out in the United States [11]. The analytic hierarchy process was employed and was found to be highly comparable with other valuation methods such as conjoint analysis. The results found that public preference is strongest for the environmental and agricultural attributes of farmland. The abovementioned studies provide scientific approaches to the decision-making process on environmental management. Yet economics has remarkable potential to be an indicator on environmental management. Consequently, economic parameters should be considered [12-13]. The current study meets this gap by considering economic parameters in the existing literature.

In addition to a scientific point of view, several multicriteria decision-making applications have been supported by public authorities. The potential to support complex decision problems for environmental or sustainability policies has been stressed [14]. Consequently, decision support systems are a developing topic that includes all stakeholders. The main aim of this study was to investigate the following questions:

1. European Union countries studied here have high agricultural production values with only small amounts of land. Do those countries use agri-environmental policies in a historical process while providing food security?

2. Are economic indicators a statistically explanatory variable in decision-making processes at the governmental level?

\section{Materials and Methods}

Our research data on Germany, France, the Netherlands, and Turkey encompass 1980, 1990, 2000, and 2013. The selected data are from the FAOSTAT database [14]. Various agro-economic and environmental indicators are tested in current research that also investigates measuring agricultural sustainability. These indicators are per capita cereals, per capita meat production, per capita milk production, yield of cereals, economic value of agricultural production, fertilizer and pesticide use efficiency, and total agricultural emissions. The study attempts to rank countries according to sustainability criteria. In the studies of ranking, multi-criteria decision-making (MCDM) methods are best suited for effectively dealing with a number of multifaceted evaluation criteria. There are several MCDM methods that can serve as ranking tools for implementing company rankings, such as AHP (analytical hierarchy process), ANP (analytic network process), TOPSIS, etc. The current study employs TOPSIS to rank the countries according to above-mentioned criteria in terms of successful historical land use policies.

TOPSIS is "an approach to identify an alternative which is closest to the ideal solution and farthest from the negative ideal solution in a multi-dimensional computing space" [15]. It has numerous advantages and is a simple process that is easy to use and programmable. The number of steps remains the same regardless of the number of attributes [16]. A disadvantage is that its use of Euclidean distance does not consider the correlation of attributes. It is difficult to weigh attributes and keep consistency of judgment, especially with additional attributes.

TOPSIS has been used in supply chain management and logistics, design, engineering and manufacturing systems, business and marketing management, environmental management, human resources management, and water resources management. This is another method where its ease of use has kept its application popular. Many of the uses seen in the literature review had TOPSIS confirm the answers proposed by other MCDM methods [17]. The advantage of its simplicity and its ability to maintain the same amount of steps regardless of problem size has allowed it to be utilized quickly to review other methods or to stand on its own as a decision-making tool [18-19].

The TOPSIS method is based on five computation steps [20]. The first step is the gathering of the performances of the alternatives on the different criteria. These 
Table 1. Criteria and alternatives in TOPSIS analysis.

\begin{tabular}{|c|c|c|c|c|}
\hline & $\begin{array}{c}\text { Criterion } \\
\text { I }\end{array}$ & $\begin{array}{c}\text { Criterion } \\
\text { II }\end{array}$ & $\cdots$ & $\begin{array}{c}\text { Criterion } \\
\text { N }\end{array}$ \\
\hline Alternative 1 & $\mathrm{X}_{11}$ & $\mathrm{X}_{12}$ & $\cdots$ & $\mathrm{X}_{1 \mathrm{n}}$ \\
\hline Alternative 2 & $\mathrm{X}_{21}$ & $\mathrm{X}_{22}$ & $\cdots$ & $\mathrm{X}_{2 \mathrm{n}}$ \\
\hline$:$ & $:$ & $:$ & $:$ & \\
\hline Alternative $\mathrm{n}$ & $\mathrm{X}_{\mathrm{m} 1}$ & $\mathrm{X}_{\mathrm{m} 2}$ & $\cdots$ & $\mathrm{X}_{\mathrm{mn}}$ \\
\hline & $\mathrm{W}_{1}$ & $\mathrm{~W}_{2}$ & $\cdots$ & $\mathrm{W}_{\mathrm{n}}$ \\
\hline
\end{tabular}

performances need to be normalized in the second step. The normalized scores are then weighted and the distances to an ideal and anti-ideal point are calculated. The performances of $n$ alternatives $a$ with respect to $m$ criteria $i$ are collected in a decision matrix $\mathbf{X}=\left(x_{i a}\right)$ as in Table 1, where $i=1, \ldots, m$ and $a=1, \ldots, n$.

The performances of the different criteria are normalized to compare the measure on different units (e.g., pounds, years, ....). Several normalization methods are available in literature [21]. Ideal normalization was preferred for minimized parameters, and maximized parameters existed in the study. The ideal normalization requires dividing each performance by the highest value in each column if the criterion has to be maximized. If the criterion has to be minimized, each performance is divided by the lowest score in each column.

$$
\mathrm{r}_{\mathrm{ai}}=\mathrm{x}_{\mathrm{ai}} / u_{a}^{+} \text {for } a=1, \ldots, n \text { and } i=1, \ldots, m \text {, }
$$

$\ldots$ where $u_{a}^{+}=\max \left(\mathrm{x}_{\mathrm{ai}}\right)$ for all $\mathrm{a}=1, \ldots, \mathrm{n}$;

$$
\mathrm{r}_{\mathrm{ai}}=\mathrm{x}_{\mathrm{ai}} / u_{a}^{-} \text {for } a=1, \ldots, n \text { and } i=1, \ldots, m \text {, }
$$

...where $u_{a}^{-}=\min \left(\mathrm{x}_{\mathrm{ai}}\right)$ for all $\mathrm{a}=1, \ldots, \mathrm{n}$.

A weighted normalized decision matrix is constructed at the second level by multiplying the normalized scores $r_{a i}$ by their corresponding weights $w_{i}$ :

$$
\mathrm{v}_{\mathrm{ai}}=\mathrm{w}_{\mathrm{i}} \cdot \mathrm{r}_{\mathrm{ai}}
$$

The criteria's weights were determined by the research team because the research is spread over a large geographic area. Survey methods could be useful if costs and time are unimportant. Yet this could be impossible in large geographic areas. The criterias' weights were as follows:

- Per capita cereals (0.25);

- Per capita meat production (0.25);

- Per capita milk production (0.2);

- Yield of cereals (0.1);

- Economic value of agricultural production (0.05);

- Fertilizer and pesticide use efficiency (0.05);

- Total agricultural emissions (0.05).

The weighted scores will be used to compare each action to an ideal (zenith) and anti-ideal virtual action. There are three different ways of defining these virtual actions.
One of them is to collect the best and worst performance on each criterion of the normalized decision matrix [22]. For the ideal action we have:

$$
\mathrm{A}^{+}=\left(\mathrm{v}_{1}^{+}, \ldots, \mathrm{v}_{\mathrm{m}}^{+}\right)
$$

And for the anti ideal action

$$
\mathrm{A}^{-}=\left(\mathrm{v}_{1}^{-}, \ldots, \mathrm{v}_{\mathrm{m}}^{-}\right)
$$

...where $\mathrm{v}_{\mathrm{i}}^{+}=\max _{\mathrm{a}}\left(\mathrm{v}_{\mathrm{ai}}\right)$ if criterion $i$ is to be maximized and $\mathrm{v}_{\mathrm{i}}^{-}=\min \left(\mathrm{v}_{\mathrm{ai}}\right)$ if criterion $i$ is to be minimized. The following formulas were used to find the distance for each action to the ideal action:

$$
d_{a}^{+}=\sqrt{\sum_{i}\left(v_{i}^{*}-v_{a i}\right)^{2}}
$$

and the anti-ideal action,

$$
d_{a}^{-}=\sqrt{\sum_{i}\left(v_{i}^{-}-v_{a i}\right)^{2}}
$$

$\ldots$ where $\mathrm{a}=1, \ldots, \mathrm{m}$. And finally, the relative closeness coefficient of each action is found using the following formula:

$$
\mathrm{C}_{\mathrm{a}}=\mathrm{d}_{\mathrm{a}}^{-} /\left(\mathrm{d}_{\mathrm{a}}^{+}+\mathrm{d}_{\mathrm{a}}^{-}\right)
$$

The closeness coefficient is always between 0 and 1 , where 1 is the preferred action. If an action is closer to the ideal than the anti-ideal, then $C_{a}$ approaches 1 , whereas if an action is closer to the anti-ideal than to the ideal, $C_{a}$ approaches 0 .

\section{Results and Discussion}

According to TOPSIS results, in 1980 the country closest to optimal solution was Turkey, with 0.75 points, and the Netherlands was farthest from optimal solution with 0.24 points. Germany and France had 0.56 and 0.74 points, respectively. In 2013 the country closest to optimal solution was France, with 0.59 points (Table 2).

We can infer from the results that all countries except for the Netherlands moved away from efficiency. Secondly, economic indicators have some effects on the ideal solution because the Netherlands have less agricultural land, but agri-economic value is higher than other countries.

\section{Conclusions}

This research that investigates the general impacts of the agriculture sector of selected countries stresses the 
Table 2. Closeness calculation in TOPSIS model.

\begin{tabular}{|c|c|c|c|c|}
\hline \multicolumn{5}{|c|}{ (1980) } \\
\hline & \multicolumn{4}{|c|}{ Ideal normalization } \\
\hline & Germany & France & Netherlands & Turkey \\
\hline $\mathrm{da}+$ & 0.224 & 0.081 & 1.027 & 0.101 \\
\hline da- & 0.374 & 0.676 & 0.109 & 0.999 \\
\hline $\mathrm{Ca}$ & 0.372 & 0.893 & 0.096 & 0.908 \\
\hline $\operatorname{sqroot}(\mathrm{da}+)$ & 0.473 & 0.284 & 1.014 & 0.318 \\
\hline sqroot(da-) & 0.612 & 0.822 & 0.330 & 0.999 \\
\hline $\mathrm{Ca}$ & 0.564 & 0.743 & 0.246 & 0.759 \\
\hline \multicolumn{5}{|c|}{ Closeness calculation (1990) } \\
\hline & \multicolumn{4}{|c|}{ Ideal normalization } \\
\hline & Germany & France & Netherlands & Turkey \\
\hline $\mathrm{da}+$ & 0.107 & 0.026 & 0.435 & 0.096 \\
\hline da- & 0.190 & 0.304 & 0.100 & 0.404 \\
\hline $\mathrm{Ca}$ & 0.640 & 0.920 & 0.187 & 0.807 \\
\hline $\operatorname{sqroot}(\mathrm{da}+)$ & 0.327 & 0.162 & 0.659 & 0.310 \\
\hline sqroot(da-) & 0.436 & 0.552 & 0.316 & 0.635 \\
\hline $\mathrm{Ca}$ & 0.571 & 0.772 & 0.324 & 0.671 \\
\hline \multicolumn{5}{|c|}{ Closeness calculation (2000) } \\
\hline & \multicolumn{4}{|c|}{ Ideal normalization } \\
\hline & Germany & France & Netherlands & Turkey \\
\hline $\mathrm{da}+$ & 0.087 & 0.039 & 0.166 & 0.101 \\
\hline da- & 0.071 & 0.144 & 0.102 & 0.131 \\
\hline $\mathrm{Ca}$ & 0.446 & 0.788 & 0.381 & 0.565 \\
\hline $\operatorname{sqroot}(\mathrm{da}+)$ & 0.296 & 0.197 & 0.407 & 0.317 \\
\hline sqroot(da-) & 0.266 & 0.379 & 0.320 & 0.362 \\
\hline $\mathrm{Ca}$ & 0.473 & 0.658 & 0.440 & 0.533 \\
\hline \multicolumn{5}{|c|}{ Closeness calculation (2013) } \\
\hline & \multicolumn{4}{|c|}{ Ideal normalization } \\
\hline & Germany & France & Netherlands & Turkey \\
\hline $\mathrm{da}+$ & 0.066 & 0.045 & 0.105 & 0.083 \\
\hline da- & 0.050 & 0.094 & 0.082 & 0.069 \\
\hline $\mathrm{Ca}$ & 0.432 & 0.675 & 0.438 & 0.453 \\
\hline $\operatorname{sqroot}(\mathrm{da}+)$ & 0.257 & 0.213 & 0.324 & 0.289 \\
\hline sqroot(da-) & 0.224 & 0.307 & 0.286 & 0.263 \\
\hline $\mathrm{Ca}$ & 0.466 & 0.591 & 0.469 & 0.476 \\
\hline
\end{tabular}

importance of the production secured from per unit area (productivity and efficiency). The efficiency strategies need to be taken into consideration with effectiveness strategies. Yet a mechanism that can evaluate the management strategies that are used in agriculture are not developed in most areas of Europe. Statistically, European lands seem to be poor in terms of excessive use of pesticides and inorganic fertilizers. Also, the contributions to global climate change, due to agricultural production, have been increased, thus the EU's agricultural production might be shifted to the $10+2+1$ countries that have newly joined the Union.

The agricultural products processing industry may be more developed in the EU-15 countries. The success of the Netherlands and Germany on this issue is clear. Another policy recommendation is where European countries that have poor agri-environmental management systems can pay an agricultural "pollution tax" to European countries that have sustainable agriculture. In this way, Europe can take a step to a future with better agriculture. Economic considerations may help to understand the environmental indicators, which have an inclusive role in creating agri-environmental policies. Consequently, economic data should be used in multi-criteria decision-making studies.

Although this research seems to be a study that ranks the countries at first glance, the countries might also be evaluated individually because they may have different natural resource levels, population potential, and other socio-economic circumstances. These are considered current research limitations. All EU countries could be included for further analysis. Therefore, some historical comparisons can give more points of view about comprehensive policy implications. Additional studies should survey weights of criteria with all stakeholders from related countries.

\section{References}

1. BEHZADIAN M., OTAGHSARA S. K., YAZDANI M., IGNATIUS J. Review: A state-of the-art survey of TOPSIS applications. Expert Systems with Applications: An International Journal 39, 13051, 2012.

2. CHEN P.C., SU H.J., MA H.W. Trace anthropogenic arsenic in Taiwan-Substance flow analysis as a tool for environmental risk management. Journal of Cleaner Production 53, 13, 2013.

3. REN Lİ., LIU J.T. Health Evaluation of a Lake Wetland Ecosystem based on the TOPSIS Method. Journal of Polish Journal of Environmental Studies 23, 2183, 2014.

4. JOZI S.A., MAJD N.M. Health, safety, and environmental risk assessment of steel production complex in central Iran using TOPSIS. Environmental Monitoring and Assessment 186, 6969, 2014.

5. VULEVIC T., DRAGOVİC N. KOSTADINOV S., SIMİC S. B., MILOVANOVIC I. Prioritization of Soil Erosion Vulnerable Areas Using Multi-Criteria Analysis Methods. Journal of Polish Journal of Environmental Studies 21 (1), 317, 2015.

6. JIANG Y., LIUU Y.S., YING G.G., HONG W.W., LİANG Y.Q., CHEN X.W. A new tool for assessing sediment quality based on theWeight of Evidence approach and grey TOPSIS. Science of the Total Environment 537, 369, 2015.

7. MIR M.A., GHAZVINEI P.T., SULAIMMAN N.M.N., BASRI N.E.A., SAHERİ S., MAHMOOD N.Z., JAHAN A., BEGUM R.A., AGHAMOHAMMADİ N. Application of 
TOPSIS and VIKOR improved versions in a multi criteria decision analysis to develop an optimized municipal solid waste management model. Journal of Environmental Management 166, 109, 2016.

8. GUIMARES B., SIMOES P., MARQUES R.C. Does performance evaluation help public managers? A balanced scorecard approach in urban waste services. Journal of Environmental Management 91, 2632, 2010.

9. AHMADİ Z., DEHAGHİ M.R., MEYBODİ M.E., GOODARZI M., AGHAJANI M. Pollution Levels in Iranian Economy Sectors Using Input-Output Analysis and TOPSIS Technique: An Approach to Sustainable Development. Social and Behavioral Sciences 141, 1363, 2014.

10. YEE S.H., CARRIGER J.F., BRADLEY P., FISHER W.S., DYSON B. Developing scientific information to support decisions for sustainable coral reef ecosystem services. Ecological Economics 115, 39, 2015.

11. DUKE J.M., AULL-HYDE R. Identifying public preferences for land preservation using the analytic hierarchy process. Ecological Economics 42, 131, 2002.

12. GAMPER C.D., TURCANU C. On the governmental use of multi-criteria analysis. Ecological Economics 62, 298, 2007.

13. DA CRUZ N., MARQUES R. A multi-criteria model to determine the sustainability level of water services. Water Asset Management International, 9, 16, 2013.

14. FAO Food and Agriculture Organization Statistical Office (FAOSTAT) database, 2014.

15. QİN X., HUANG G., CHAKMA A., NIE X., LİN Q.A
MCDM-based expert system for climate-change impact assessment and adaptation planning - A case study for the Georgia Basin, Canada. Expert Systems with Applications, 34 (3), 2164, 2008.

16. IC Y. An experimental design approach using TOPSIS method for the selection of computer-integrated manufacturing technologies. Robotics and Computer-Integrated Manufacturing, 28, 245, 2012.

17. BOULANGER P., BRECHET T. Models for policy-making in sustainable development: The state of the art and perspectives for research. Ecological Economics 55, 337, 2005.

18. MURALIDHAR P., RAVINDRANATH K., SRIHARI V. Evaluation of Green Supply Chain Management Strategies Using Fuzzy AHP and TOPSIS P. Journal of Engineering 2, 824, 2012.

19. VELASQUEZ M., HESTER P.T. An Analysis of MultiCriteria Decision Making Methods. International Journal of Opreration Research 10, 56, 2013.

20. ISHIZAKA A., NEMERY P. Multi-Criteria Decision Analysis Methods and Software. Wiley Publishing, UK, 2013.

21. ZHANG X., GAO L., BARRETT D., CHEN Y. Multi-criteria evaluation of water management for sustainable development in mining. $20^{\text {th }}$ International Congress on Modelling and Simulation, Adelaide, Australia, 1-6 December 2013.

22. JOZİ A.S., SAFFARİAN S., SHAFIEE M. Environmental Risk Assessment of a Gas Power Plant Exploitation Unit Using Integrated TOP-EFMEA Method. Journal of Polish Journal of Environmental Studies 21, 95, 2012. 